\title{
Effects of Artichoke Leaf Extract on Acute Gastric Mucosal Injury in Rats
}

\author{
Kazuo Ishida, ${ }^{a}$ Ryoji Koлmмa, ${ }^{b}$ Makoto Tsubor,${ }^{c}$ Yuka Tsuda, ${ }^{c}$ and Mikio Ito ${ }^{*, a, b}$ \\ ${ }^{a}$ Laboratory of Analytical Pharmacology, Graduate School of Environmental and Human Sciences, Meijo University; \\ ${ }^{b}$ Laboratory of Analytical Pharmacology, Faculty of Pharmacy, Meijo University; 150 Yagotoyama, Tenpaku-ku, Nagoya \\ 468-8503, Japan: and ${ }^{c}$ Ichimaru Pharcos Co., Ltd.; 318-1 Asagi, Motosu, Gifu 501-0491, Japan.
}

Received July 15, 2009; accepted October 6, 2009

The present study was designed to clarify the effects of an ethanol extract of artichoke leaf on acute gastric mucosal injury in rats. Oral administration of artichoke leaf extract dose-dependently prevented absolute ethanol-induced $(125-500 \mathrm{mg} / \mathrm{kg})$ or restraint plus water immersion stress-induced gastric mucosal injury $(1000-2000 \mathrm{mg} / \mathrm{kg})$. The artichoke leaf extract contains $1 \%$ cynaropicrin and $0.8 \%$ chlorogenic acid as main components and $70 \%$ dextrin as a vehicle. Cynaropicrin at doses of 1/100 of artichoke leaf extract [ethanol-induced mucosal injury: $5 \mathrm{mg} / \mathrm{kg}$, per os (p.o.); stress-induced mucosal injury: $20 \mathrm{mg} / \mathrm{kg}$, p.o.] also prevented gastric mucosal injury in both animal models. However, dextrin and chlorogenic acid at doses contained in the leaf extract were ineffective in both models. When artichoke leaf extract was given orally to normal rats, it (500 $2000 \mathrm{mg} / \mathrm{kg}$, p.o. $)$ dose-dependently increased gastric mucus content. In addition, it (125-500 mg/ $/ \mathrm{kg}$, p.o.) dosedependently prevented the decrease in gastric mucus content by absolute ethanol. When the effects of artichoke leaf extract on basal gastric acid secretion in rats were evaluated, it $(500-2000 \mathrm{mg} / \mathrm{kg}$, p.o. $)$ dose-dependently increased the volume of gastric juice in normal rats. However, it was ineffective in decreasing basal gastric acid secretion in normal rats. These results indicate that artichoke leaf extract is effective against acute gastritis and its beneficial effect is due to that of cynaropicrin. The gastric mucus-increasing action of artichoke leaf extract may be, at least in part, related to the anti-gastritic action of the extract.

Key words artichoke leaf extract; cynaropicrin; anti-gastritic action; gastric mucus

Artichoke (Cynara Scolymus L.) is a plant that is widely grown in Mediterranean countries, including southern France and California in the United States. It is rich in natural antioxidants. In general, the dried extract consisting of leaves and not flowering heads of artichoke has been eluted with water in European countries and the main components are caffeoylquinic acid derivatives (cynarin and chlorogenic acid), flavonoids (luteolin and apigenin) and bitters (cynaropicrin). ${ }^{1-4)}$ Artichoke leaf extract has been used for hepatoprotective $^{5,6)}$ and cholesterol reducing ${ }^{7,8)}$ purposes. Based on in vitro ${ }^{5,9,10)}$ and in vivo ${ }^{6,11)}$ studies, it is believed that artichoke leaf extract is very effective as an antioxidant and its beneficial effects are attributed to its antioxidant action. However, there is still no experimental evidence indicating which components possess the beneficial effects.
Artichoke leaf extract used in the present study was extracted by $45 \%$ ethanol and contains $1 \%$ cynaropicrin and $0.8 \%$ chlorogenic acid, $1.3 \%$ protein, $0.1 \%$ lipid, $3.0 \%$ ash, $21.3 \%$ carbohydrate and $2.5 \%$ water and $70 \%$ dextrin was added as a vehicle (Fig. 1A). Thus, cynaropicrin and chlorogenic acid are contained as the main components (Fig. 1B) and other components such as cynarin, luteolin and apigenin are not contained in this extract. Artichoke leaf extract is currently used in Germany and Switzerland as a remedy for indigestion. ${ }^{4)}$ It is believed that bitter compounds such as cynaropicrin are responsible for the beneficial effects. It has been reported that cynaropicrin from Saussurea lappa has in vitro anti-inflammatory effects via its inhibition of the production of inflammatory mediators. ${ }^{12}$

Acute gastritis is produced by psychological or physical

A

\begin{tabular}{|c|c|c|c|c|c|c|c|c|}
\hline \multirow{2}{*}{ Components } & \multicolumn{5}{|c|}{ Ethanol extract of artichoke leaf } & \multirow{2}{*}{ Dextrin } \\
\cline { 2 - 10 } & Cynaropicrin & Chlorogenic acid & Protein & Lipid & Ash & Carbohydrate & Water & \\
\hline Content \% & 1.0 & 0.8 & 1.3 & 0.1 & 3.0 & 21.3 & 2.5 & 70.0 \\
\hline
\end{tabular}

B

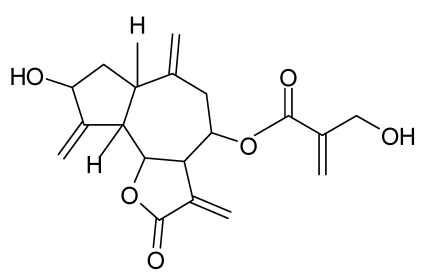

Cynaropicrin<smiles>O=C(/C=C\c1ccc(O)c(O)c1)OC1CC(O)C(O)CC1(O)C(=O)O</smiles>

Chlorogenic acid

Fig. 1. Components in Artichoke Leaf Extract (A) and Chemical Structures of Cynaropicrin and Chlorogenic Acid (B) 
stress, alcohol and drugs such as steroidal or nonsteroidal anti-inflammatory drugs. The beneficial effects of artichoke leaf extract on acute gastritis have not yet been sufficiently examined in experimental studies. Therefore, in the present study, we investigated the effects of artichoke leaf extract containing cynaropicrin and chlorogenic acid on absolute ethanol- or restraint plus water immersion stress-induced acute hemorrhagic gastric mucosal injury in rats, and compared the effects to those of sofarcone, an anti-ulcer agent. Furthermore, in order to clarify the mechanisms of the gastric cytoprotective action of artichoke leaf extract, we examined the effects of artichoke leaf extract on gastric mucus content and basal gastric acid secretion in rats.

\section{MATERIALS AND METHODS}

Animals Male Sprague-Dawley strain SPF rats (Nippon SLC, Shizuoka, Japan) weighing 180-200 g, were used in the experiment. The animals were housed in an air-conditioned room at $23 \pm 1^{\circ} \mathrm{C}$. All experimental procedures described were approved by the Experimental Animal Research Committee of Meijo University, Faculty of Pharmacy.

Materials The materials used were artichoke leaf extract and the components in the extract (dextrin, cynaropicrin and chlorogenic acid). Cynaropicrin and chlorogenic acid were mixed with dextrin $[1 \%(\mathrm{wt} / \mathrm{wt})$ cynaropicrin or $1 \%(\mathrm{wt} / \mathrm{wt})$ chlorogenic acid $+99 \%$ (wt/wt) dextrin. These materials were supplied by Ichimaru Pharcos Co., Ltd. (Gifu, Japan) Sofalcone $\left(\right.$ Solon $\left.^{\circledR}\right)$ (Taisho Pharmaceutical Co., Ltd., Tokyo, Japan) and omeprazole (Fujisawa Astra, Osaka, Japan), antiulcer drugs, were used as comparative drugs.

Measurement of Ethanol-Induced Gastric Mucosal Injury After the rats were fasted for $24 \mathrm{~h}$, absolute ethanol was administered in a volume of $1 \mathrm{ml}$ per $100 \mathrm{~g}$ of body weight into their stomachs. Each test material (artichoke leaf extract, dextrin, chlorogenic acid, cynaropicrin and sofalcone) was given orally in a volume of $1 \mathrm{ml}$ per $100 \mathrm{~g}$ of body weight $2 \mathrm{~h}$ prior to ethanol administration. Distilled water as a control was given instead of test material. One hour after treatment with the necrotizing agent, the animals were killed under ether anesthesia, and then the stomach was removed and opened along the greater curvature. In order to evaluate the degree of gastric mucosal lesions, photographs of hemorrhagic erosions in the glandular stomach were taken with a DP50 digital camera (OLYMPUS, Tokyo, Japan) and the total area of erosions was then measured with Win ROOF software (Mitani Shoji, Fukui, Japan). The degree of gastric mucosal injury was expressed as the mucosal lesion index $\left(\mathrm{mm}^{2}\right)$.

Measurement of Restraint Plus Water Immersion Stress-Induced Gastric Mucosal Injury After the rats were fasted for $24 \mathrm{~h}$, each test material (artichoke leaf extract, dextrin, chlorogenic acid, cynaropicrin and sofalcone) was given orally in a volume of $1 \mathrm{ml}$ per $100 \mathrm{~g}$ of body weight. Control animals were administered distilled water orally instead of test material. Two hours after the administration of test material or distilled water, the animals were restrained in stress cages and immersed in $23^{\circ} \mathrm{C}$ water. Four hours after the stress load, the animals were killed under ether anesthesia, and the stomach was removed and opened along the greater curvature. The total area of gastric mucosal erosions was measured and the degree of gastric mucosal injury was expressed as the mucosal lesion index $\left(\mathrm{mm}^{2}\right)$ as mentioned above in the measurement of ethanol-induced gastric mucosal injury.

Measurement of Gastric Mucus Content before and after Oral Administration of Ethanol The rats were fasted for $24 \mathrm{~h}$ in order to evaluate the effects of test materials on gastric mucus content before ethanol treatment. After fasting, each test material (artichoke leaf extract, cynaropicrin and sofalcone) or distilled water was given orally in a volume of $1 \mathrm{ml}$ per $100 \mathrm{~g}$ of body weight. Two hours after the administration of a test material or distilled water, the animals were killed under ether anesthesia and the mucus content in gastric mucosa was determined by staining the mucus with $0.1 \%$ alcian blue according to the method of Kitagawa et al. ${ }^{13)}$

In order to evaluate the effects of test materials on gastric mucosal injury and gastric mucus content after ethanol treatment, the rats were fasted for $24 \mathrm{~h}$. Test material or distilled water was given orally $2 \mathrm{~h}$ before absolute ethanol treatment. One hour after ethanol treatment, the animals were killed under ether anesthesia, and the degree of gastric mucosal injury was expressed as the mucosal lesion index $\left(\mathrm{mm}^{2}\right)$ as described above. After the lesion index was measured, the mucus content in gastric mucosa was determined as mentioned above.

Measurement of Basal Gastric Acid Secretion The rats were deprived of food but allowed free access to water for $24 \mathrm{~h}$. After fasting, a test material (artichoke leaf extract, cynaropicrin and omeprazole) or distilled water was given orally. Two hours after administration of test material or distilled water, the pylorus of each rat was ligated under ether anesthesia. The gastric juice was collected for $3 \mathrm{~h}$ after ligation. The volume of gastric juice was measured, the acidity was determined using an automatic titrator (ABT-101, Tohadenpa, Tokyo, Japan) and total acid output during the 1-h period was calculated.

Statistical Analyses The results obtained are expressed as the mean \pm S.E.M. The data were analyzed by one-way analysis of variance, and the statistical significance among groups was determined by Tukey-Kramer's multiple-range test. In all cases, $p<0.05$ was considered significant.

\section{RESULTS}

Effects of Artichoke Leaf Extract, the Components and Sofalcone on Ethanol-Induced Gastric Mucosal Injury Intragastric administration of absolute ethanol to control rats produced large hemorrhagic injury in the glandular stomach. Artichoke leaf extract at oral doses of 125, 250 and $500 \mathrm{mg} / \mathrm{kg}$ dose-dependently prevented the gastric mucosal injury by $43 \%, 95 \%$ and $99 \%$, respectively (Fig. 2A). When the effects of the components contained in $500 \mathrm{mg} / \mathrm{kg}$ of artichoke leaf extract were evaluated, dextrin $[495 \mathrm{mg} / \mathrm{kg}$, per os (p.o.)] and chlorogenic acid $(4 \mathrm{mg} / \mathrm{kg}$, p.o.) given as a mixture of dextrin [396 mg/kg, p.o., 99\% (wt/wt) of the mixture] were ineffective in preventing the mucosal injury (Fig. 2B). Cynaropicrin at an oral dose of $5 \mathrm{mg} / \mathrm{kg}$ given as a mixture with dextrin [495 mg/kg, p.o., 99\% (wt/wt) of the mixture] markedly prevented the mucosal injury by $98 \%$ (Fig. 2B). Sofalcone, a comparative drug, at an oral dose of $100 \mathrm{mg} / \mathrm{kg}$ 
A

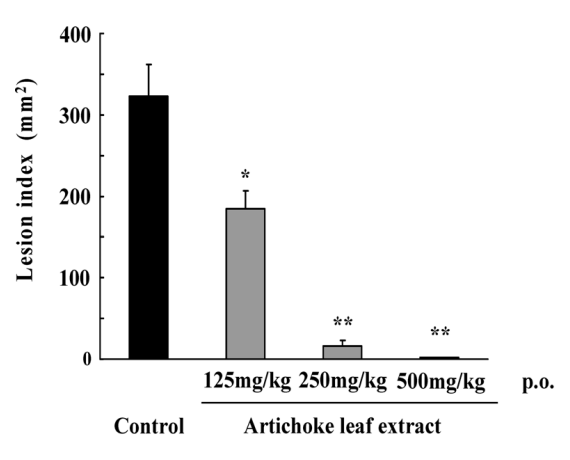

B

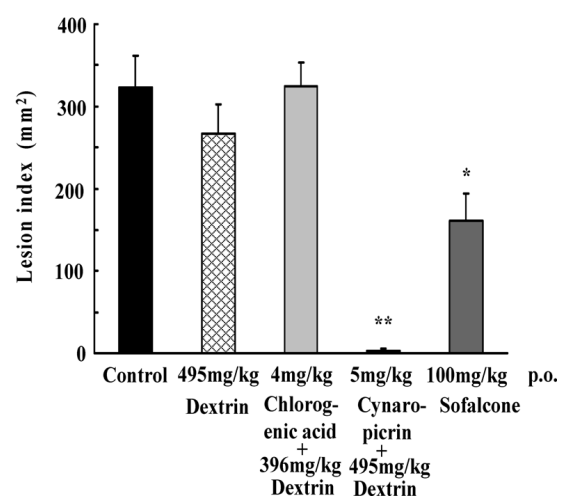

Fig. 2. Effects of Artichoke Leaf Extract (A), the Components (B) and Sofalcone (B) on Ethanol-Induced Gastric Mucosal Injury in Rats

Artichoke extract or other test material was given orally $2 \mathrm{~h}$ prior to intragastric instillation of absolute ethanol. The effects of test materials on gastric mucosal injury were evaluated $1 \mathrm{~h}$ after ethanol instillation. Each column denotes the mean \pm S.E.M. for 6 rats. Significantly different from control, $* p<0.05, * * p<0.01$.

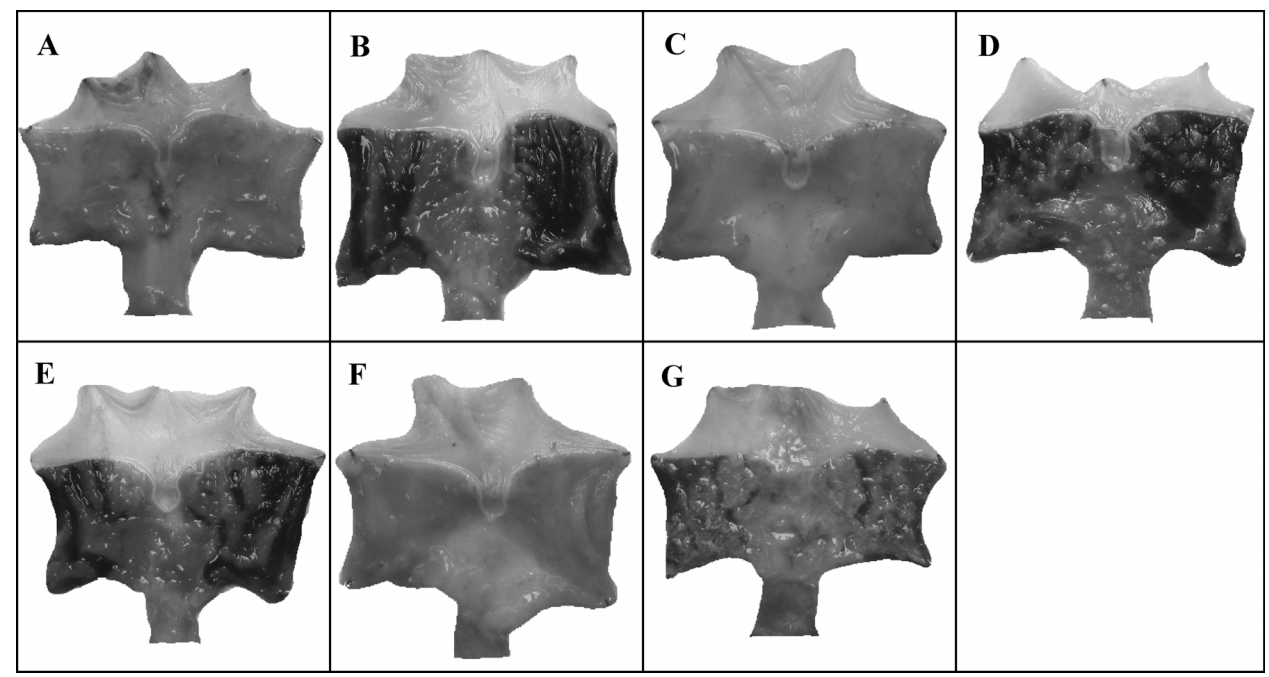

Fig. 3. Representative Photographs of Rat Gastric Mucosa in Absolute Ethanol-Induced Gastric Mucosal Injury

A: normal, B: control, C: artichoke leaf extract ( $500 \mathrm{mg} / \mathrm{kg}$, p.o.), D: dextrin (495 mg/kg, p.o.), E: chlorogenic acid (4 mg/kg, p.o.) + dextrin (396 mg/kg, p.o.), F: cynaropicrin $(5 \mathrm{mg} / \mathrm{kg}$, p.o. $)+\operatorname{dextrin}(495 \mathrm{mg} / \mathrm{kg}$, p.o. $)$, G: sofalcone $(100 \mathrm{mg} / \mathrm{kg}$, p.o. $)$.

prevented the gastric mucosal injury by $50 \%$ (Fig. $2 \mathrm{~B}$ ). Thus, cynaropicrin at an oral dose of 1/100 of artichoke leaf extract showed a preventive effect equal to that of the extract. Representative photographs of the gastric mucosa are shown in Fig. 3.

Effects of Artichoke Leaf Extract, the Components and Sofarcone on Restraint Plus Water Immersion-Induced Gastric Mucosal Injury The restraint plus water immersion stress loading to control rats for $4 \mathrm{~h}$ produced hemorrhagic injury in the glandular stomach. Artichoke leaf extract at oral doses of 1000,1500 and $2000 \mathrm{mg} / \mathrm{kg}$ dose-dependently prevented the stress-induced gastric mucosal injury by 33\% (not significantly), 84\% and 99\%, respectively (Fig. $4 \mathrm{~A})$. When the effects of the components containing in $2000 \mathrm{mg} / \mathrm{kg}$ of artichoke leaf extract were evaluated, dextrin (1980 mg/kg, p.o., 99\% of the extract) and chlorogenic acid $(16 \mathrm{mg} / \mathrm{kg}$, p.o. $)$ given as a mixture of dextrin $(1584 \mathrm{mg} / \mathrm{kg}$, p.o., $99 \%$ of the mixture) were ineffective in preventing the mucosal injury (Fig. 4B). Cynaropicrin at an oral dose of $20 \mathrm{mg} / \mathrm{kg}$ given as a mixture with dextrin $(1980 \mathrm{mg} / \mathrm{kg}$, p.o. $)$ completely prevented the mucosal injury by $99 \%$ (Fig. 4B).
On the other hand, sofalcone, at an oral dose of $200 \mathrm{mg} / \mathrm{kg}$, prevented the gastric mucosal injury by 64\% (Fig. 4B). Representative photographs of gastric mucosa are shown in Fig. 5.

Effects of Artichoke Leaf Extract, Cynaropicrin and Sofalcone on Gastric Mucus Content in Normal Rats Artichoke leaf extract at oral doses of 500, 1000 and $2000 \mathrm{mg} / \mathrm{kg}$ increased gastric mucus content by $26 \%$ (not significantly), 51\% and 79\%, respectively, in a dose-dependent manner, compared to the control in normal rats (Fig. 6). However, the extract at oral doses of 125 and $250 \mathrm{mg} / \mathrm{kg}$ was ineffective in increasing the mucus content (data not shown). Cynaropicrin at an oral dose of $20 \mathrm{mg} / \mathrm{kg}$ given as a mixture with dextrin $(1980 \mathrm{mg} / \mathrm{kg}$, p.o.) markedly increased the mucus content by $135 \%$, although at an oral dose of $5 \mathrm{mg} / \mathrm{kg}$ $(+$ dextrin $495 \mathrm{mg} / \mathrm{kg}$, p.o.) it only showed a slight increase $(50 \%)$. Sofalcone at an oral dose of $200 \mathrm{mg} / \mathrm{kg}$ significantly increased the mucus content by $66 \%$, although at an oral dose of $100 \mathrm{mg} / \mathrm{kg}$ it did not show an obvious increase.

Effects of Artichoke Leaf Extract, Cynaropicrin and Sofalcone on Gastric Mucus Content after Intragastric 
A

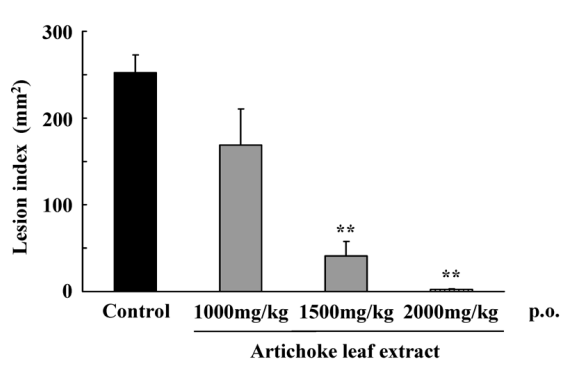

B

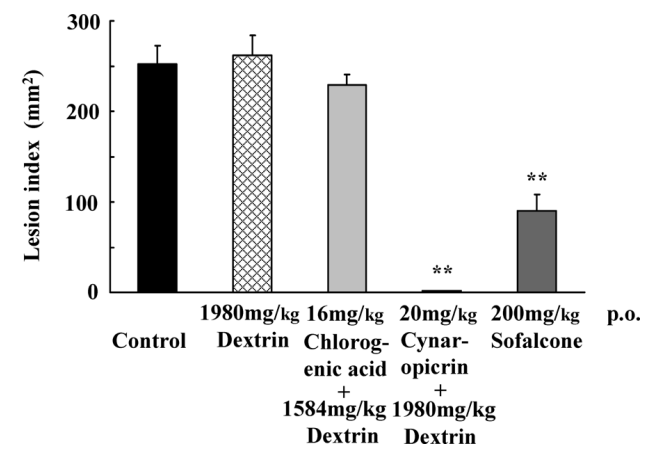

Fig. 4. Effects of Artichoke Leaf Extract (A), the Components (B) and Sofalcone (B) on Restraint Plus Water Immersion Stress-Induced Gastric Mucosal Injury in Rats

Artichoke leaf extract or other test material was given orally $2 \mathrm{~h}$ prior to stress load. The effects of test materials on gastric mucosal injury were evaluated $4 \mathrm{~h}$ after stress load. Each column denotes the mean \pm S.E.M. for 6 rats. Significantly different from control, $* * p<0.01$.

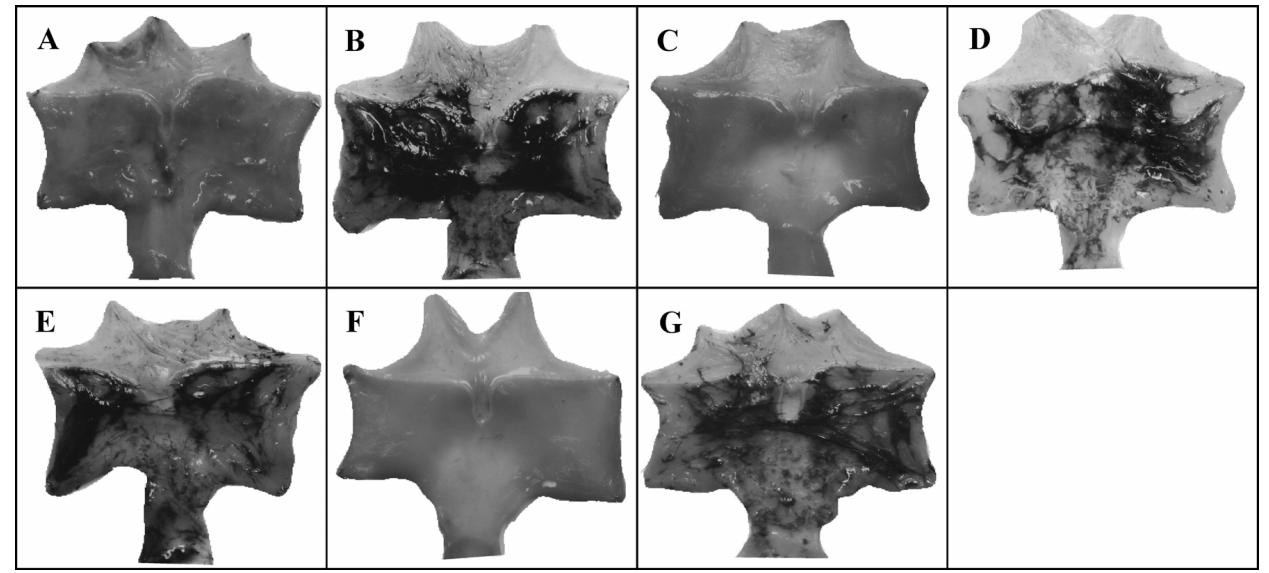

Fig. 5. Representative Photographs of Rat Gastric Mucosa in Restraint Plus Water Immersion-Induced Gastric Mucosal Injury

A: normal, B: control, C: artichoke leaf extract ( $2000 \mathrm{mg} / \mathrm{kg}$, p.o.), D: dextrin $(1980 \mathrm{mg} / \mathrm{kg}$, p.o. $)$, E: chlorogenic acid (16 mg/kg, p.o.) + dextrin (1584 mg/kg, p.o.), F: cynaropicrin $(20 \mathrm{mg} / \mathrm{kg}$, p.o. $)+$ dextrin $(1980 \mathrm{mg} / \mathrm{kg}$, p.o. $)$, G: sofalcone $(200 \mathrm{mg} / \mathrm{kg}$, p.o. $)$.

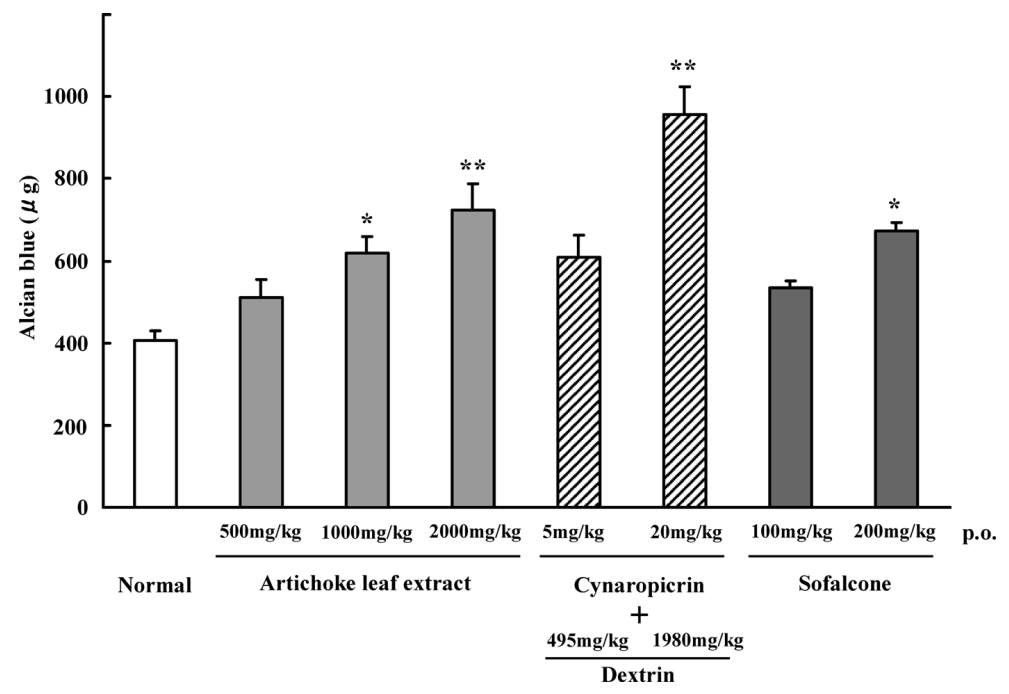

Fig. 6. Effects of Artichoke Leaf Extract, Cynaropicrin and Sofalcone on Gastric Mucus Content in Normal Rats

The effects of test materials on gastric mucus content in normal rats were evaluated $2 \mathrm{~h}$ after administration of test materials. Each column denotes the mean \pm S.E.M. for 6 rats. Significantly different from control, $* p<0.05, * * p<0.01$.

Administration of Ethanol The preventive effects of artichoke extract and cynaropicrin given as a mixture with dextrin and sofalcone on absolute ethanol-induced gastric mucosal injury were almost equal to the results shown in Fig. 2 (data not shown). The gastric mucus content in absolute ethanol-treated control rats was $48 \%$ lower than that in the ethanol-untreated normal rats (Fig. 7). Artichoke leaf extract at oral doses of 125,250 and $500 \mathrm{mg} / \mathrm{kg}$ dose-dependently 
increased the mucus content by $46 \%, 60 \%$ and $187 \%$, respectively, compared to that of ethanol-treated control. Cynaropicrin at an oral dose of $5 \mathrm{mg} / \mathrm{kg}$ given as a mixture with dextrin $(495 \mathrm{mg} / \mathrm{kg}$, p.o. $)$ and sofarcone at an oral dose of $100 \mathrm{mg} / \mathrm{kg}$ markedly increased the mucus content by $131 \%$ and $167 \%$, respectively, compared to that of ethanol-treated control.

Effects of Artichoke Leaf Extract, Cynaropicrin and Omeprazole on Basal Gastric Acid Secretion Artichoke leaf extract at oral doses of 500,1000 and $2000 \mathrm{mg} / \mathrm{kg}$ dosedependently increased the volume of gastric juice by 1.5 (not significantly), 2.5- and 2.9-fold, compared to the control (Fig. 8A). However, the extract at oral doses of 125 and $500 \mathrm{mg} / \mathrm{kg}$ did not affect the volumes of gastric juice (data not shown). Cynaropicrin at an oral dose of $20 \mathrm{mg} / \mathrm{kg}$ given as the mixture with dextrin $(1980 \mathrm{mg} / \mathrm{kg}$, p.o. $)$ markedly increased the volume by 2.3 -fold. However, artichoke leaf extract $(500,1000,2000 \mathrm{mg} / \mathrm{kg}$, p.o. $)$ and cynaropicrin $(20 \mathrm{mg} / \mathrm{kg}$, p.o. $)$ given as a mixture of dextrin $(1980 \mathrm{mg} / \mathrm{kg}$, p.o.) did not affect total acid output (Fig. 8B). Omeprazole $(50 \mathrm{mg} / \mathrm{kg}$, p.o. $)$, a comparative drug, markedly decreased

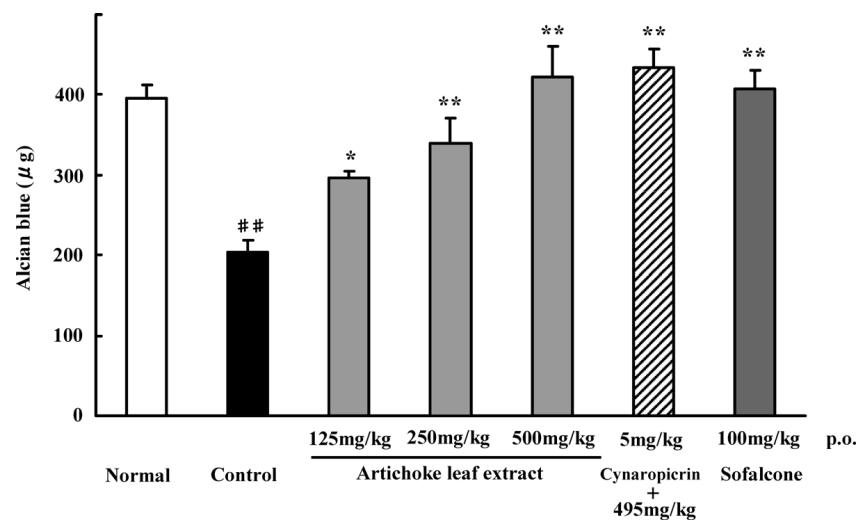

Fig. 7. Effects of Artichoke Leaf Extract, Cynaropicrin and Sofalcone on Gastric Mucus Content after Intragastric Administration of Ethanol

Artichoke leaf extract or test material was given orally $2 \mathrm{~h}$ prior to intragastric administration of absolute ethanol and the effects of test materials on gastric mucus content were evaluated $1 \mathrm{~h}$ after ethanol treatment. Each column denotes the mean \pm S.E.M. for 6 rats. Significantly different from normal (ethanol-untreated), $\# p<0.01$. Significantly different from control, $* p<0.05, * * p<0.01$. total acid output by $95 \%$ (Fig. 8 B), although it showed no apparent effect on the volume of gastric juice (Fig. 8A).

\section{DISCUSSION}

The results of the present study indicate that artichoke leaf extract prevents ethanol-induced or restraint plus water immersion stress-induced acute gastric mucosal injury in rats, at least in part, by its gastric mucus-increasing action. Furthermore, the results demonstrated that the anti-gastritic action (gastric cytoprotective action) of artichoke leaf extract is mainly due to that of cynaropicrin, and not chlorogenic acid.

In the present experiments, artichoke leaf extract dose-dependently prevented ethanol-induced $(125-500 \mathrm{mg} / \mathrm{kg}$, p.o. $)$ or stress-induced gastric mucosal injury $(1000-2000 \mathrm{mg} / \mathrm{kg}$, p.o.). In artichoke leaf extract eluted by $45 \%$ ethanol, cynaropicrin and chlorogenic acid are the main components. Of these two main components, cynaropicrin at an oral dose of 1/100 of artichoke extract (ethanol-induced injury: $5 \mathrm{mg} / \mathrm{kg}$; stress-induced injury: $20 \mathrm{mg} / \mathrm{kg}$ ) showed gastric cytoprotective actions equal to those of the extract in both experimental models. On the other hand, chlorogenic acid and dextrin, a vehicle, were ineffective in protecting gastric injuries in both animal models. In addition, other components (protein, lipid, ash or carbohydrate) were also ineffective (data not shown). Therefore, the present results indicate that the beneficial effects of artichoke extract on acute hemorrhagic gastritis are mainly due to that of cynaropicrin and not other components. It is worth noting that cynaropicrin at extremely small doses exhibited more beneficial effects than those of sofalcone.

It has been demonstrated that oxygen-derived free radicals are involved in the pathogenesis of ethanol-induced gastric mucosal injury. ${ }^{14,15)}$ Ethanol-induced gastric mucosal injury has also been suggested to be due to impairments in defensive factors such as mucus ${ }^{16)}$ and mucosal microcirculation ${ }^{17)}$ in addition to free radicals. On the other hand, the major factors implicated in the development of stress-induced gastric mucosal injury include an increase in gastric acid secretion and a decrease in mucosal protection due to the reductions in mucus secretion, mucosal blood flow and prostaglandin biosynthesis. ${ }^{18)}$ Therefore, in the next experiments, in order
A

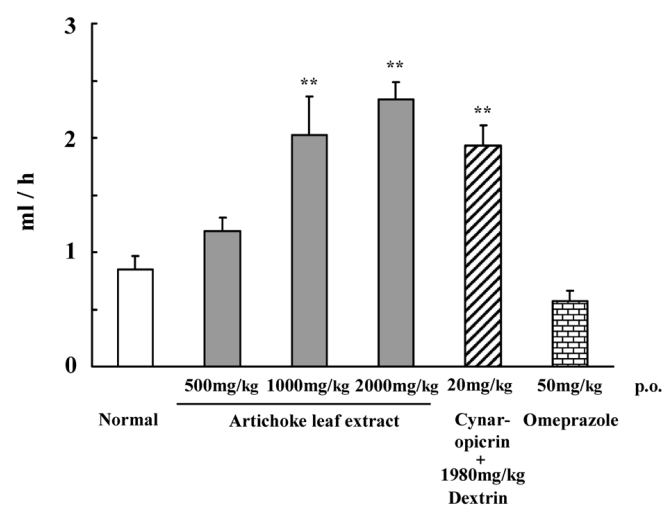

B

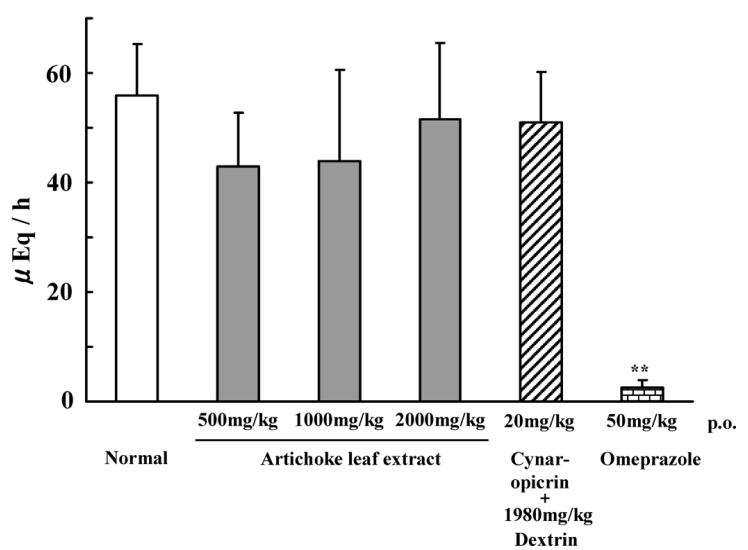

Fig. 8. Effects of Artichoke Leaf Extract, Cynaropicrin and Omeprazole on Basal Gastric Secretion (A: Volume of Gastric Juice; B: Total Acid Output)

Artichoke leaf extract or test material was given orally $2 \mathrm{~h}$ prior to pylorus ligation and the gastric juice was collected for $3 \mathrm{~h}$ after the ligation. Each column denotes the mean \pm S.E.M. for 6 rats. Significantly different from control, $* * p<0.01$. 
to clarify the mechanisms of the gastric cytoprotective action of artichoke leaf extract, we examined the effects of artichoke leaf extract and cynaropicrin on the content of gastric mucus in rats, before and after ethanol treatment as a defensive factor against gastric mucosa. In addition, we examined the effects of both test samples on basal gastric acid secretion as an aggressive factor against gastric mucosa in normal rats. The results showed that artichoke leaf extract at 500$2000 \mathrm{mg} / \mathrm{kg}$, p.o. and cynaropicrin at $5-20 \mathrm{mg} / \mathrm{kg}$, p.o. dosedependently increased gastric mucus content $2 \mathrm{~h}$ after administration to normal rats. Mikami et al. ${ }^{19)}$ reported that the activity of uridine $5^{\prime}$-diphosphate (UDP)-galactosyltransferase, a key enzyme in the synthesis of mucus glycoprotein, markedly increased in rat gastric mucosa treated with geranylgeranylacetone (GGA), cetraxate hydrochloride (CET), or prostaglandin $\mathrm{E}_{1}\left(\mathrm{PGE}_{1}\right)$. They suggested based on this result that GGA and CET may exert anti-ulcer effects by increasing mucus glycoprotein synthesis and that endogenous PG synthesis may be involved in this process. It is suggested from their report that a marked increase in gastric mucus content by oral administration of artichoke extract or cynaropicrin to normal rats may be due to the increased synthesis of mucus glycoprotein mediated by endogenous PGs. When gastric mucus content was measured $1 \mathrm{~h}$ after intragastric administration of absolute ethanol to rats, the mucus content had decreased by $48 \%$, compared with that of ethanoluntreated ones. Artichoke leaf extract at $125-500 \mathrm{mg} / \mathrm{kg}$, p.o. and cynaropicrin at $5 \mathrm{mg} / \mathrm{kg}$, p.o. markedly prevented the decrease in gastric mucus content produced by intragastric ethanol instillation, when they were administered $2 \mathrm{~h}$ prior to ethanol treatment. Tsukada et al. ${ }^{20)}$ observed in in vitro experiments that higher concentration of ethanol $(0.5-1.5 \mathrm{M})$ caused a marked reduction in mucus glycoprotein synthesis and that the addition of ornoprostil, a $\mathrm{PGE}_{1}$ analog, improved the synthesis and secretion of glycoprotein in the presence of ethanol. In connection with mucus glycoprotein synthesis, Kobayashi et al. ${ }^{21)}$ reported that water-immersion stress lasting $7 \mathrm{~h}$ in rats induced gastric lesions and a marked reduction in endogenous $\mathrm{PGE}_{2}$ and prostaglandin $\mathrm{I}_{2}\left(\mathrm{PGI}_{2}\right)$ levels. In addition, they demonstrated that gefarnate, an anti-ulcer agent, inhibited water immersion-induced gastric lesions and the reduction of $\mathrm{PGE}_{2}$ and $\mathrm{PGI}_{2}$ levels. It is suggested from the above findings that the reduced gastric mucus content produced by intragastric ethanol instillation may be caused by the reduction of mucus glycoprotein synthesis mediated most likely by endogenous PGs. In addition, artichoke leaf extract and cynaropicrin may prevent the decrease in the mucus content by ethanol via the increased synthesis of mucus glycoprotein. A relationship was observed between the prevention of ethanol-induced gastric mucosal injury and the increase in gastric mucus content by artichoke leaf extract or cynaropicrin (Fig. 9). These results suggest that artichoke leaf extract and cynaropicrin may protect, at least in part, the mucosa against absolute ethanol- or restraint plus water immersion stress-induced gastric mucosal damage by increasing mucosal defensive factors such as gastric mucus.

In the present study, artichoke leaf extract (500$2000 \mathrm{mg} / \mathrm{kg}$, p.o.) and cynaropicrin $(20 \mathrm{mg} / \mathrm{kg}$, p.o.) significantly increased the volume of gastric juice after $3 \mathrm{~h}$ pylorus ligation, although they were ineffective in decreasing total acid output. As described in the Introduction, artichoke leaf

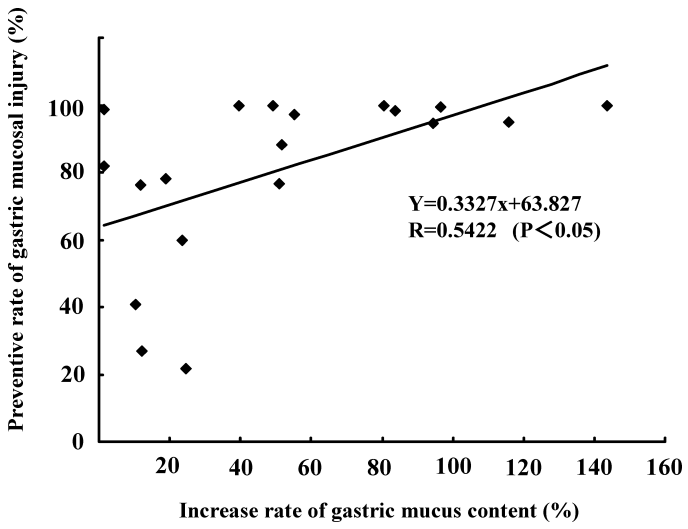

Fig. 9. Relationship between the Prevention of Ethanol-Induced Gastric Mucosal Injury and the Increase in Gastric Mucus Content by Artichoke Leaf Extract and Cynaropicrin

extracts are currently used in Germany and Switzerland as a remedy for indigestion. ${ }^{4}$ Cynaropicrin, which is contained in artichoke leaf extract, possesses a bitter taste. Therefore, it is considered that cynaropicrin increased the volume of gastric juice by stimulating the secretion of saliva and gastric juice, because it has actions as a bitter stomachic. Furthermore, it is possible that artichoke extract and cynaropicrin prevented absolute ethanol-induced gastric mucosal injury via dilution of the ethanol concentration in the stomach by increasing the volume of gastric juice. In the present preliminary experiment, gastric juice was not detected at all in the stomach of any animals $2 \mathrm{~h}$ after oral administration of higher doses of artichoke extract, although a small volume of gastric juice was observed at $1 \mathrm{~h}$. Therefore, in order to evaluate the effects of artichoke leaf extract and other test materials on ethanol-induced gastric mucosal injury, we administered test materials orally $2 \mathrm{~h}$ prior to the intragastric instillation of ethanol.

In the present study, we first demonstrated that artichoke leaf extract prevents both acute gastric mucosal injuries in rats via its gastric mucus-increasing action.

In summary, the results of the present study indicate that artichoke leaf extract has beneficial effects on acute hemorrhagic gastritis, at least in part, by its gastric mucus glycoprotein-increasing action. Further studies are needed to clarify whether or not the mucus-increasing action of artichoke extract is mediated by endogenous PGs or not.

\section{REFERENCES}

1) Llorach R., Espin J. C., Tomas-Barberan F. A., Ferreres F., J. Argric. Food Chem., 50, 3458-3464 (2002).

2) Wang M., Simon J. E., Aviles I. F., He K., Zheng Q. Y., Tadmor Y., J. Agric. Food Chem., 51, 601-608 (2003).

3) Joy J. F., Haber S. L., Am. J. Health Syst. Pharm., 64, 1906-1909 (2007).

4) Holtmann G., Adam B., Haag S., Collet W., Grunewald E., Windeck T., Aliment. Pharmacol. Ther, 18, 1099-1105 (2003).

5) Gebhardt R., Toxicol. Appl. Pharmacol., 144, 279-286 (1997).

6) Aktay G., Deliorman D., Ergun E., Ergun F., Yesilada E., Cevik C., J. Ethnopharmacol., 73, 121-129 (2000).

7) Pittler M. H., Thompson C. J., Ernst E., Cochrane Database Syst. Rev., 3, CD003335 (2002).

8) Rafe B., Ann F. W., Richard W. M. Carol W., Hugh C. R. S., Phytomedicine, 15, 668-675 (2008).

9) Brown J. E., Rice-Evans C. A., Free Radic. Res., 29, 247-255 (1998). 
10) Perez-Garcia F., Adzet T., Canigueral S., Free Radic. Res., 33, 661665 (2000).

11) Speroni E., Cervellati R., Govoni P., Guizzardi S., Renzulli C., Guerra M.C., J. Ethnopharmacol., 86, 203-211 (2003).

12) Cho J. Y., Baik K. U., Jung J. H., Park M. H., Eur. J. Pharmacol., 398, $399-407$ (2000).

13) Kitagawa H., Takeda F., Kohei H., Arzneimittelforchung, 36, 1240 1244 (1986).

14) Mizui T., Sato H., Hirose F., Doteuchi M., Life Sci., 41, 755-763 (1987).

15) Tepperman B. L., Soper B. D., Can. J. Phisiol. Pharmacol., 68, $207-$ 210 (1990).

16) Kuwata H., Ishihara K., Kakei M., Ohara S., Okabe H., Hotta K., Jpn. J. Gastroenterol., 82, 28-33 (Abstract in English) (1985).
17) Trier J. S., Szabo S., Allan C. H., Gastroenterology, 92, 13-22 (1987).

18) Moody F. G., Cheung L. Y., Simons M. A., Zalewsky C., Dig. Dis., 21, $148-154$ (1976).

19) Mikami Y., Mizuno M., Maga T., Kihara Y., Yoshinaga F., Tanaka S., Yunoki N., Kawahara T., Okada H., Tsuji T., Acta Med. Okayama, 51, 245-249 (1997).

20) Tsukada H., Seino Y., Jo I., Tatsuta H., Ito K., Hashimoto A., Kotera T., Matsubayashi Y., Mori Y., Ito A., Ueda S., Ohkuma M., Sakai M., Nippon Shokakibyo Gakkai Zasshi, 87, 2342-2351 (Abs. in English) (1990).

21) Kobayashi K., Arakawa T., Nakamura H., Chono S., Yamada H., Satoh H., Ono T., Tohoku J. Exp. Med., 140, 181-185 (1983). 